\title{
A CASE OF CONSTRUCTIONAL POLYSEMY IN LATIN
}

\author{
LAURA A. MICHAELIS \\ University of California, Berkeley
}

\begin{abstract}
In this paper, I will examine the syntactic and semantic properties of a Latin correlative construction, the so-called comparative conditional. I will investigate the extent to which this construction inherits its formal and interpretive features from constructions needed independently in the grammar. While the syntactic properties of the comparative conditional are highly motivated, the semantics of the construction is idiosyncratic: there is evidence to indicate that the construction is polysemous, having two related scalar interpretations.
\end{abstract}

\section{Introduction 1}

The construction at issue is the Latin manifestation of a form-meaning pairing that is readily identifiable cross-linguistically, but has only recently captured the attention of linguistic theorists. Following McCawley (1988), I will refer to this construction as the comparative conditional. With respect to its semantic and syntactic properties, the Latin comparative conditional has much in common with the English sentence type exemplified by the proverb The bigger they come, the harder they fall. An example of the Latin construction is given in (1):

(1) Quanto in pectore hanc rem meo how-much:ABL in heart:ABL this:ACC matter:ACC my:ABL magis voluto, tanto $m i$ more ponder:1sG:PRES:IND:ACT that-much:ABL me:DAT aegritudo auctior est in animo. grief:NOM greater:NOM is:3SG:PRES:IND in spirit:ABL 
'The more I turn this matter over in my mind, the greater the grief is in my soul.'

Plautus, Captivi 781-2

Like its English analog, the Latin comparative conditional expresses a relationship between an independent and dependent variable. Thus, sentence (1) can be paraphrased in the following manner: 'any increase in the duration of deliberation yields a concomitant increase in the amount of grief experienced'. Syntactically, both comparative conditional constructions are biclausal, and contain a comparative phrase in each clause. The structure of the English comparative conditional has been of interest to proponents of a theory of grammar which recognizes the existence of grammatical constructions, and, in particular, formal idioms. Analysts like Fillmore (1987), Fillmore, Kay and O'Connor (1988) and McCawley have been especially interested in the following issue: to what extent is the comparative conditional syntax derivable from more basic constructions, and to what extent are its component parts - and the manner in which they are combined - unique to this structural pattern? Each argues that the English comparative conditional inherits certain syntactic properties from those constructions which it resembles semantically. Hence, the comparative conditional, like conditional constructions, suppresses future will from its "protasis". The comparative conditional also displays characteristics of comparative constructions (e.g., ordinary comparative morphology). A number also note, however, that (a) there is no established category label for the definite article in its function here as a degree marker; and (b) standard phrase-structure rules do not provide for the pairing of parallel clauses of exactly this type. Thus, the English comparative conditional represents an extragrammatical structural pattern.

By contrast, I will argue, the syntax of the Latin comparative conditional is highly regular: the complex construction is assembled from component parts provided independently by the grammar. Thus, for example, the Latin comparative conditional appears to inherit its basic structure from the correlative template, whereby a subordinate clause introduced by a relative element is paired with a main clause containing a demonstrative element of the same lexical category. Some semantic properties of the Latin comparative conditional are also attributable to this general correlative construction. I maintain, however, that the Latin comparative conditional represents a construction in its own right. The Latin comparative conditional 
cannot be reduced to the grammatical configurations from which it is built up - primarily because certain of these component parts do not have the interpretations with which they are associated elsewhere.

The semantic structure of the comparative conditional is idiosyncratic primarily because the construction imposes a special interpretation upon the paired comparative phrases [CompPhrases] within it. For our purposes, the CompPhrase consists of a morphologically comparative element - an adjective, adverb or quantity noun - and one of several ablative-case degree modifiers, e.g., tanto auctior ('the greater') in sentence (1). The comparative element and its degree modifer need not be contiguous. The semantics of the CompPhrase is constructionally specific in two respects: (a) the CompPhrase has two alternate readings; (b) in one of these readings, the comparative form per se makes no discernible semantic contribution.

Within the comparative conditional, the CompPhrase may code a variable across a range of scalar values, or it may code a fixed point upon a scale. An example of the first interpretation is given in (1). Here, the CompPhrases quanto magis and tanto auctior each stand for a range of values on scales of duration and magnitude, respectively. The scales in question are established by the individual paired clauses. An example of the second interpretation is given in (2); the CompPhrases are shown in boldface:

(2) Sed non statuendo felicitati modum, quanto but not setting:ABL success:DAT limit:ACC how-much:ABL
altius elatus
erat
tanto
foedius
higher lifted:NOM was:3SG:IMPERF:IND that-much:ABL worse conruit.

fell:3SG:PERF:IND

'But by not setting a limit to his success, to the extent that he [M. Atilius] had risen high, he fell badly.'

Livy 30.30

In (2), each of the CompPhrases codes a fixed point on the respective scales of height attained and severity of downfall suffered.

The variable interpretation of the CompPhrase (1) is not unique to the comparative conditional; it is associated with the comparative outside of the comparative conditional. This use of the comparative involves a comparative standard that is not fixed. Hence, in both English and Latin, the comparative is a means of coding the accretion of a scalar property, as in (3): 


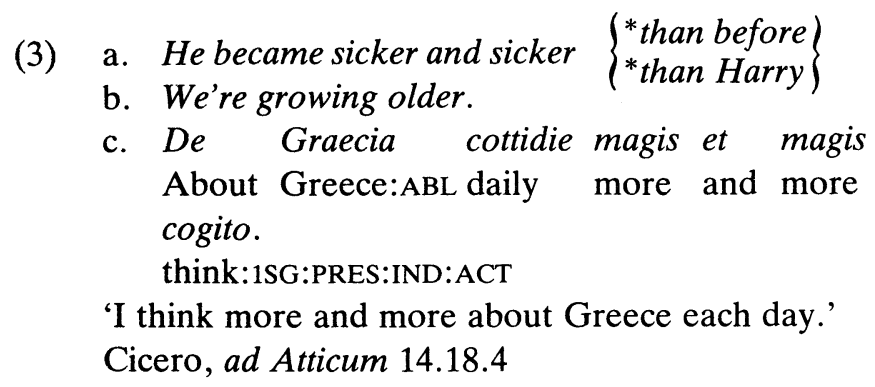

By contrast, the constant interpretation of the CompPhrase exemplified in (2) seems to owe nothing to the semantics of comparison. One might say that in such examples the morphological comparative does not represent a semantic comparative. An understanding of the general range of functions of the comparative will not help a naive decoder (i.e., one ignorant of the comparative conditional construction per se) to interpret (2).

The two possible interpretations of the CompPhrase render the Latin comparative conditional polysemous. That is, the syntactic template whose properties will be described forthwith - can express either of two types of relationships between a pair of semantic scales: (a) a link between two variables, whose ranges are determined by the two scales; or (b) an equivalence between two fixed values on the two scales. Let us refer to the first reading as the variable reading; the second as the constant reading. Strictly speaking, neither reading is calculable from the meanings of constructional subparts. The association of the constant reading with the comparative conditional template appears particularly unsupported by the grammar at large, especially the grammar of comparison. The comparative conditional is then best regarded as a conventional pairing of syntactic form and meaning.

The remainder of this paper will be structured as follows. The next section will provide a brief overview of the syntax of the Latin comparative conditional, and the manner in which the subparts of this construction are licensed by related constructions. This section will also provide a brief synopsis of the Construction Grammar formalism used here (Fillmore and Kay 1991). The third part will further describe the two readings of the comparative conditional, and the manner in which linguistic context, in particular verbal aspect, might select a preferred reading. The concluding section will highlight the advantages of a construction-based approach to the semantic phenomena at issue. 


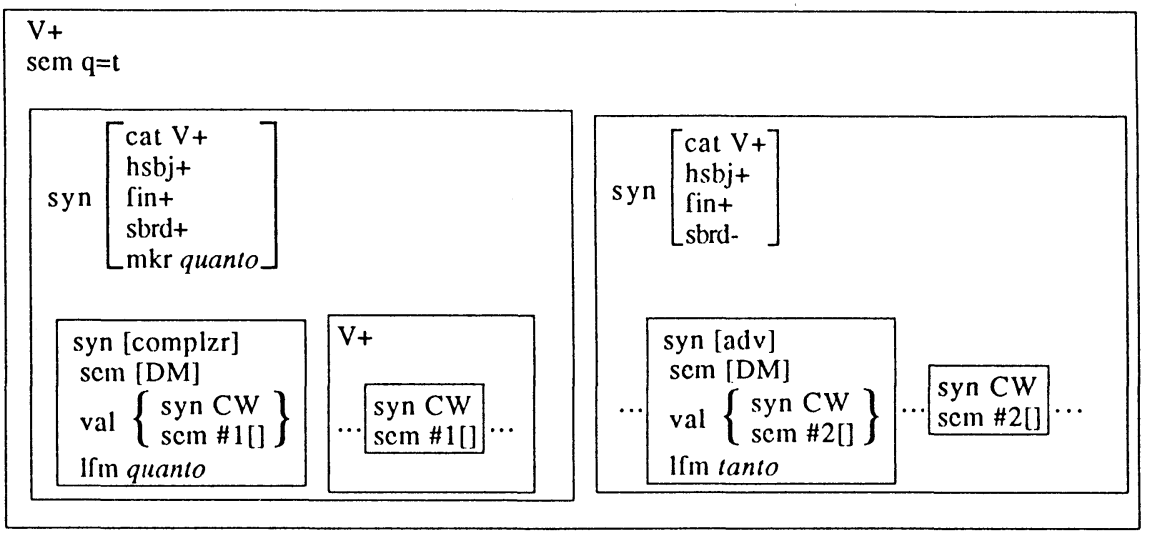

Figure 1

\section{Syntax}

The syntactic properties of the comparative conditional are represented in Figure 1, using some notational conventions of unificationbased Construction Grammar (Fillmore and Kay 1991). In Construction Grammar, constituent structure is represented by box diagrams. Each box corresponds to a node within a tree-structure representation. Syntactic constituency and semantic interpretation are simultaneously represented. Each box contains an attribute-value matrix (AVM): a list of syntactic and semantic attributes (lexical category, maximality vis-à-vis lexical projection, etc.) with exactly one value assigned to each. One such attribute is valence; the value of this attribute is the set of elements within the subcategorization frame of a lexical item or its phrasal projection. Semantic composition is accomplished through unification of semantic feature structures. According to Fillmore and Kay, "the unification of two feature structures A and B is the feature structure that contains each attribute-value pair of $A$ and also contains each attribute-value pair of B" (p. 5). Some attributes may have an unspecified value, indicated by empty square brackets []. A unification requirement upon two or more such attributes is indicated by a numbered pound sign \# next to each. Unification is also defined for structures (a collection of one or more constituents, each of which corresponds to an AVM); like structures unify via AVM unification. The topmost semantic attribute in the construction is that which contains every atomic semantic value of the 
subconstituents. In Figure 1, no semantic integration is represented. The topmost sem value indicates only that the construction as a whole asserts that two degree measures are equivalent.

As shown, the basic structure of the construction consists of a main and subordinate clause. The main clause is that containing the demonstrative degree-marker (DM) tanto (or sometimes eo or hoc). The subordinate clause contains the interrogative degree-marker quanto (the degree marker $q u o$ is also found).The subordinate status of the quanto-bearing clause is demonstrated by such sentences as (4), in which the comparative conditional appears in indirect discourse:

(4)

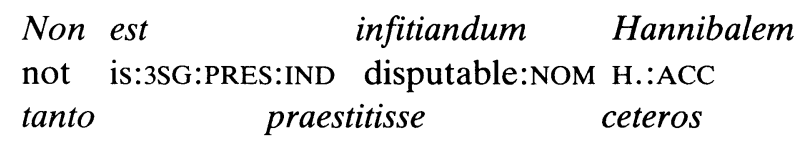

that-much:ABL surpass:INF:PERF:ACT other:ACC imperatores prudentia quanto populus generals:ACC prudence:ABL how-much:ABL people:NOM Romanus antecedat fortitudine Roman:NOM supersede:3SG:PRES:SUBJUNCT:ACT strength:ABL cunctas nationes

all:ACC nations:ACC

'One cannot dispute that Hannibal surpassed other generals in prudence to the same degree that the Roman people supersede all other nations in strength.'

Cornelius Nepos 13.1

The verb infitior ('I dispute') takes an accusative-infinitive sentential complement. Hence, Hannibal, the subject of the verb praesto ('I surpass') appears in the accusative, while the verb appears in the infinitive form. It is generally true in Latin that subordinate clauses, including relative clauses and conditional protases, retain their finite form in indirect discourse, appearing in the subjunctive. As shown in (4), the verb of the quanto-bearing clause, antecedo ('I supersede'), appears in the present subjunctive. Sentence (4) also demonstrates that the main clause may precede the subordinate clause, a stylistic inversion typical of conditional sentences. Additionally, (4) illustrates the possibility of ellipsis within the CompPhrase. In Latin, certain scalar predicates, including those denoting pre-eminence, 
represent "conceptual comparatives" (McCawley 1988). Verbs like antecedo take an object representing a comparative standard; the verb lexicalizes the notion that the comparative target (the subject) manifests some property to a greater degree than does the standard. The property itself is often coded by an ablative of specification, like fortitudine ('in strength'). Since such verbs inherently express a comparison, they may be directly modified by the degree marker, without the intercession of a comparative word. Such sentences as (4) represent fixed-value correlatives akin to (2).

Within the paired clauses, only one element has a fixed position: the degree marker quanto. In the subordinate clause, it must appear in initial position; wh-elements tend to be so constrained. By contrast, the degree modifier tanto may appear in clause-initial position (1-2), post-subject position (4), or clause-final position, as in (5):

(5) Quanto diutius abest, magis

how-much:ABL longer absent:ISG:PRES:IND more

cupio tanto.

want:1SG:PRES:IND:ACT that-much:ABL

'The longer he is away, the more I long for [him].'

Terence, Heautontimoroumenos 3.1.15

Quanto, it seems, plays two roles: it functions both as a subordinating conjunction and as a degree modifer of the comparative element within the clause. The demonstrative degree marker has only the latter of these functions. It is hence found in all positions within the main clause, as indicated by the ellipses on either side of the tanto constituent. The valence requirements of both degree markers call for a comparative word (CW). The comparative word is freely ordered within each clause with respect to its degree marker; this is again indicated by ellipses flanking the comparative word. What I have called the CompPhrase - the degree marker plus comparative - represents a discontinuous constituent. The degree word and comparative word need not appear in tandem. Nonetheless, the language shows a preference for an ordering in which the comparative word immediately follows its degree modifier, and these degree modifiers appear in clause-initial position. This default pattern is exemplified in (6); CompPhrases are shown in boldface: 


\section{(6) Quo}

propius hostis

accedebat,

how-much:ABL closer enemy:NOM came:3SG:IMP:IND:ACT

eo maior caedes fugientium

that-much:ABL greater:NOM slaughter:NOM fugitives:GEN fiebat.

became:3PL:IMPERF:IND

'The nearer the enemy approached, the greater the slaughter of fugitives became.'

Livy 26.9

It is evident that the comparative conditional template schematized in Figure 1 inherits its syntactic properties from two more basic constructions: the correlative construction and the adverbially modified comparative. The correlative construction provides for the pairing of a subordinate and main clause, in which the subordinate clause contains a relative element and the main clause a demonstrative element of the same lexical category - nominal, adjectival or adverbial. As in the comparative conditional, the relative element serves as a complementizer. Some examples of the general correlative construction are given in (7). The correlative words appear in boldface; the lexical category of the pair is also indicated:
a. Tot
mala
passus
sum
that-many misfortunes:ACC suffered:NOM am:1SG:PRES:IND
quot in aethere sidera lucent.
as-many in sky:ABL constellations:NOM shine:3PL:PRES:IND
'I have endured as many misfortunes as constellations shine in the sky.'
Ovid, Tristia 1.5.47 (adverbial)

b. Tam esse clemens tyrannus quam that-much be:INF:PRES mild:NOM tyrant:NOM so-much rex importunus potest.

king:NOM harsh:NOM can:1SG:PRES:IND

'A tyrant can be as mild as a king is harsh.'

Cicero, De Re Publica 1.33.50 (adverbial)

c. Cum esset talis

Since was:3SG:IMPERF:SUBJUNCT that-kind:NOM qualem te esse video. which-kind:ACC you:ACC be:INF:PRES see:1SG:PRES:IND:ACT 'Since he was the same as I saw you to be...' Cicero, Pro L. Murena 14.32 (adjectival) 


\section{d. Non habuit tantam rem \\ not had:3SG:PERF:IND:ACT that-great:ACC thing:ACC \\ familiarem Philus quantam Laelius \\ familiar:ACC P.:NOM as-great:ACC L.:NOM \\ 'Philus did not have as great a fortune as Laelius.' \\ Apuleius, Apologia 20 (adjectival)}

The adjectival correlative counterparts of (7d) might look familiar; these are the adjectival equivalents of the paired degree-markers appearing in the comparative conditional. These adjectives are general indicators of magnitude. As modifiers, they agree in case, number and gender with the head noun. Used substantively, they can serve as degree markers, akin to tam or quam of (7b). As degree markers, they have the invariant ablative neuter singular form, tanto, etc. This use of a quantity adjective or noun is often called the ablative of measure. Additional examples of ablatives of this type are multo 'by far' from multus ('much') and magno 'a great deal' from magnus ('great'). An ablative of measure must be accompanied by a comparative word. In this role, the ablative element indicates the degree to which the comparative target departs from a comparative standard. Examples of the ablative of measure are given in (8):

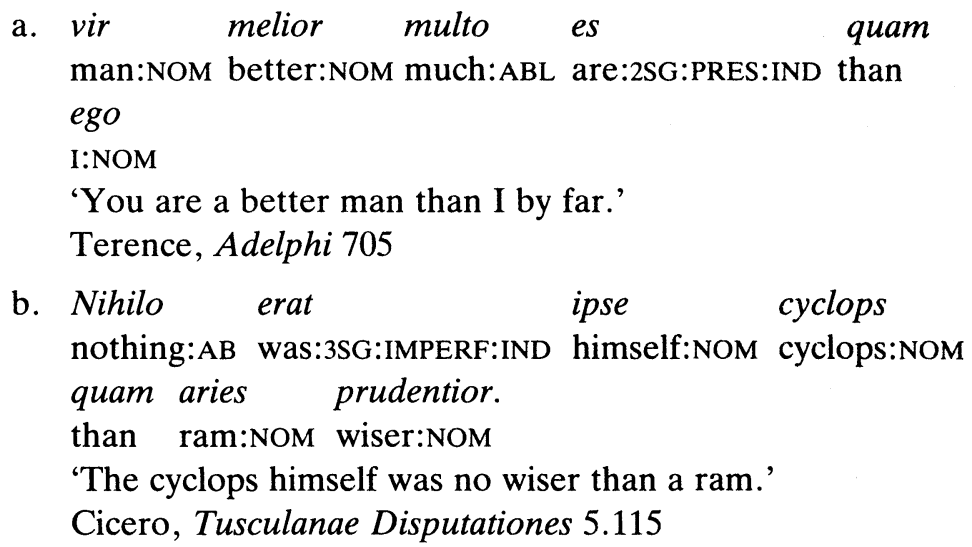

The CompPhrase within the comparative conditional is formed in accordance with the pattern exemplified in (8). The paired relative and demonstrative degree-markers are provided by the correlative construction. The latter construction, as mentioned, also provides the biclausal syntax of the comparative conditional. Hence, the syntactic template shown in Figure 1 is definable in terms of two more basic constructions: the ablative of mea- 
sure and the correlative. This regular syntax does not, however, deprive the comparative conditional of its status as an independent construction. Certain semantic characteristics of the comparative conditional are attributable to those of its grammatical building blocks; some of these traits are not, and are properly regarded as idiomatic. We might now turn to those properties.

\section{Semantics}

As shown in (7), instances of the basic correlative construction can generally be translated via the English "as...as construction". In general, the correlative expresses equivalence between two values assigned to two compared entities. These values may be qualitative, as in (7c). By using a correlative containing the relative and demonstrative adjectives qualis and talis, the speaker equates two entities, the addressee and another person known to the speaker, with respect to character. The addressee, mentioned in the relative clause, is the standard of comparison. The equated values may also be quantitative, i.e., scalar. The paired scalar values may be located on one scale or on two distinct (although commensurate) scales. ${ }^{2}$ Thus, for example, (7a) involves a single numerical scale: it asserts that the numerical value that can be assigned to the set of misfortunes is equal to that which can be assigned to the set of constellations. Sentence (7b) involves two property scales: it asserts that the degree of clemency attributable to a tyrant might equal the degree of harshness assignable to a king. In all sentences of this type, the standard of comparison is expressed by the relative-bearing subordinate clause.

The semantics of the general correlative provides the interpretive framework of the comparative conditional construction. As indicated by the topmost sem value of Figure 1, the comparative conditional expresses an equivalence between the degrees expressed by the relative and demonstrative degree markers. One can regard the comparative conditional as a biscalar correlative of the type exemplified in (7b), in which degrees of two scalar properties are equated. Thus, for example, sentence (5) evokes a scalar model in which any value assignable to length of absence is equivalent to some value assignable to the acuteness of longing.

There is, however, more to said about the semantics of the comparative conditional. Let us concentrate for now on the "variable reading" of the construction exemplified in (5-6). There are a couple of respects in which this semantic structure departs from that of the general correlative. 
These departures can be regarded as instances in which the semantic specifications of the more specific construction override those of more basic related constructions (cf. McCawley 1988). Firstly, as mentioned, sentences like (5-6) do not equate two fixed values. They equate the whole range of values that can be assumed upon the two paired scales. Secondly, the comparative conditional expresses an implicational relationship between the scalar properties expressed by the two clauses. That is, any increase in one property causes a proportionate increase in the other: in (6), the degree of nearness of the enemy determines the magnitude of the slaughter. The independent variable, like a conditional protasis, is coded by the subordinate clause.

Conditional semantics must be attributed to the comparative conditional template as a whole - as an idiosyncratic property of the comparative conditional vis-à-vis the general correlative pattern. It does stand to reason that the clause coding the comparative standard of the correlative should also code the protasis of a correlative conditional. Both protases and comparative standards code background information with respect to a main assertion. Nonetheless, if one should attempt to decode the comparative conditional armed only with knowledge of the general correlative construction, one would not necessarily know that this correlative subtype has a conditional interpretation. Further, as mentioned earlier, that the comparative conditional should express a relationship between variables - rather than an equivalence between fixed values - is not a fact about the correlative, but must be attributed to the special semantics imposed upon the CompPhrase by the comparative conditional construction.

Within the comparative conditional, the comparative necessarily expresses what I will call "moving-standard comparison". English and Latin examples of this type of comparison are given in (3). Examples (3a) and (3c) demonstrate that in both languages, moving-standard comparatives can appear in reduplicated form. The comparative standard of a movingstandard comparative is necessarily unspecified, as shown by the starred continuations of (3a). The comparative standard is simply any lower value of the coded property with respect to whatever higher values are assumed over time. Such comparatives thus code the accretion of a scalar property, and function in this manner in the comparative conditional. Within the comparative conditional, the ablative of measure, tanto or quanto, accordingly codes the degree to which the comparative target departs from the 
moving standard. As pro-adverbs, these ablative correlative elements code not a particular degree of departure (great or little) but any degree of departure from this standard. It is important to note that although movingstandard comparison is not unique to the comparative conditional, the fact that the comparative must have this specialized function within the comparative conditional is not a priori knowable. Thus, the semantics of the comparative conditional is nonpredictable, insofar as it does not simply follow from the semantics of the correlative and adverbially modified comparative.

The semantic characterization of the comparative conditional provided does not extend to sentences like (2). These sentences display all of the syntactic trappings of the comparative conditional, but are interpreted in a manner that does not involve correlated scales. As mentioned earlier, such sentences as (2) appear to express an equivalence between two fixed degrees on two scales. Further examples of this "fixed-value" reading are given in (9); CompPhrases are shown in boldface:

a. Duae Luceriam ferebant viae, two:NOM Luceria:ACC led:3PL:IMPERF:IND:ACT roads:NOM altera, patens apertaque, sed quanto one:NOM open:NOM broad-and:NOM but so-much:ABL tutior, tanto fere longior. Altera, safer:NOM that-much:ABL nearly longer:NOM other:NOM per furculas Caudinas, brevior. through forks:ACC Caudine:ACC shorter:NOM 'Two roads led to Luceria - one, open and broad. But that one was almost as long as it was safe. The other one, through the Caudine forks, was shorter.'

Livy 9.2

b. Quantum ego dolui in Caesaris how I:NOM grieved:1SG:PERF:IND:ACT in C.:GEN suavissimis litteris! Quo sweetest:ABL letter:ABL how-much:ABL

suant
$\begin{array}{ll}\text { were:3PL:IMPERF:IND sweeter:NOM letters:NOM } \\ \text { eo } & \text { maiorem dolorem illius ille } \\ \text { that-much:ABL } & \text { greater:ACC grief:NOM that:GEN that:NOM } \\ \text { casus } & \text { adferebat. } \\ \text { misfortune:NOM brought:3SG:IMP:IND:ACT }\end{array}$


'How I grieved at Caesar's extremely touching letter! To the extent that this letter was touching, the grief that his misfortune [the death of his daughter, Julia] brought was great.' Cicero, Q.F. 3.117

c. Pompeius revertit in Italiam.

P.:NOM returned: 3SG:PERF:IND:ACT in Italy:ACC

Plerique non sine exercitu venturum in many:NOM not without army:ABL come:CC in urbem adfirmarunt. Quo city:ACC claimed:3PL:PAP:IND:ACT how-much:ABL magis hoc homines timuerant, more this:ACC people:NOM feared:3PL:PAP:IND:ACT eo gratior civilis tanti that-much:ABL more-gratifying:NOM civil:GEN such:GEN imperatoris reditus fuit.

general:GEN return:NOM was:3SG:PERF:IND

'Pompey returned to Italy. Many had claimed that he would not come back without his army. To the extent that people had feared this, the return of such a leader as a civilian was gratifying.'

Velleius 2.40 .3

Semantically, these comparative conditional examples are reminiscent of biscalar correlative sentences like (7b), in which the degree markers tam and quam modify positive-degree scalar adjectives. As mentioned, sentence ( $7 b$ ) asserts that a tyrant and a king might be located at the same point on scales of clemency and harshness, respectively. Similarly, (9a), e.g., asserts that the road in question is located at the same point on the two scales of length and safety (for further discussion of this example, see footnote 3). The use of the comparative in (9) appears to be strictly pro forma; the ablative degree-marker requires a comparative word, but the comparative makes no obvious semantic contribution to these sentences. No comparative standards are apparently adduced in the interpretation of the paired CompPhrases of (9). In this reading, the comparative conditional again imposes a specialized interpretation on the CompPhrase. In this case, however, the CompPhrase is interpreted in a manner inconsistent with any of the semantic values that are otherwise attached to comparatives. ${ }^{3},{ }^{4}$

This situation, in which a construction imposes a highly idiosyncratic interpretation upon a comparative, is not unprecedented in Latin. Another 
such construction juxtaposes two descriptors of a given entity. The construction is used to assert that the entity ranks higher on one scale than on the other scale. Both properties are coded by adjectives in the comparative form. Examples are given in (10): 'The ditch was longer than it was wide.' Livy 32.38
a. Longior quam latior acies erat
b. pestilentia minacior quam pestilence:NOM more-alarming:NOM than perniciosior more-dangerous:NOM 'a pestilence more alarming than dangerous' Livy 4.52 longer:NOM than wider:NOM ditch:NOM was:3SG:IMPERF:IND

The use of the comparative form to express that property serving as the standard of comparison does not seem motivated with respect to the generally applicable semantics of comparison. Instead, a parallelism requirement of the template calls for this "extraneous comparative". One must know this double-comparative construction in order to interpret the extra comparative as one might otherwise interpret a positive adjective. By the same token, one must grasp the comparative conditional construction in order to disregard, as it were, the semantic contributions of the comparative morphemes in deriving a given instance of the constant reading.

The lack of semantic motivation for the comparative under the constant reading of the comparative conditional might make such comparatives susceptible to replacement by the positive degree; there appear to be some instances of this semantic regularization in later authors. Livy and Tacitus occasionally use the positive degree in the subordinate-clause CompPhrase. An example from Livy is given in (11); an example from Tacitus is given in (12):

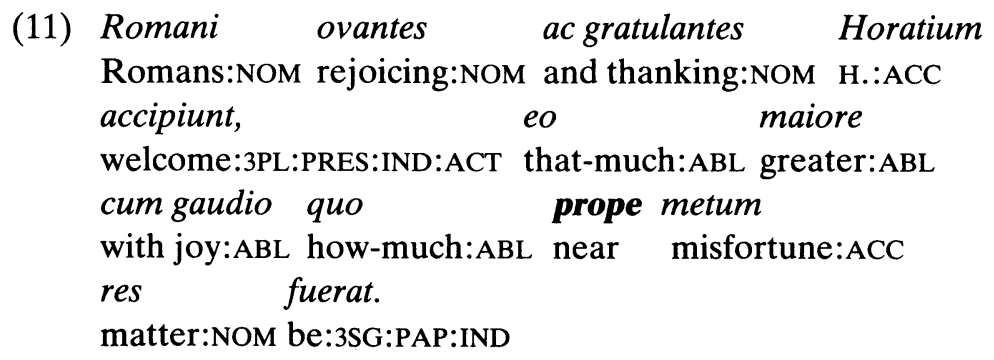


'The Romans rejoicing and expressing thanks welcome Horatius, with joy great to the degree that the matter had come near to disaster.'

Livy 1.25

(12)

Miliens sesertium in munificentia ea
Thousand sesterces:GEN in munificence:ABL that:ABL
conlocatum, tanto
invested:NOM that-much:ABL more-acceptable:NOM in

vulgum, quanto modicus privatis

people:ACC how-much:ABL modest:NOM private:ABL

aedificationibus.

building: $\mathrm{ABL}$

'One thousand sesterces was invested in that munificence. This was only as acceptable to the people as he was modest in private construction.'

Tacitus, Annales 6.45

In (11), the subordinate-clause CompPhrase contains the positive degree prope ('near') rather than the expected comparative propius ('nearer'). In (12), modicus ('modest') appears, rather than the expected modicior ('more modest'). This occasional use of the positive appears to occur only in instances of the comparative conditional which are linked to the constant reading. 5

It should be noted that the two readings of the comparative conditional exemplified in (1) and (2) are not wholly attributable to alternate interpretations of the CompPhrase. When the comparative conditional is used to assert an equivalence between fixed values it need not evoke an implicational link between the scalar properties in question. Sentence (9a), for example, simply asserts that road length and road safety are equal; it does not presuppose that safety determines length. Road length is simply a comparative standard, as per the correlative construction. Hence, the equivalency reading differs from the variable reading in that the former does not express an entailment relation. Typically, however, the equivalency reading does presuppose the existence of a correlation between values on the scales in question. Thus, sentence (9b) presupposes that the degree of pathos expressed in a letter will determine the degree to which the reader is moved. 


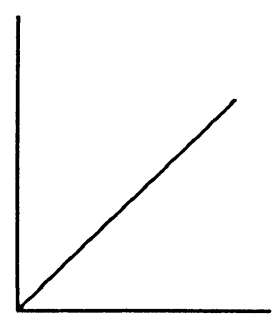

Figure 2

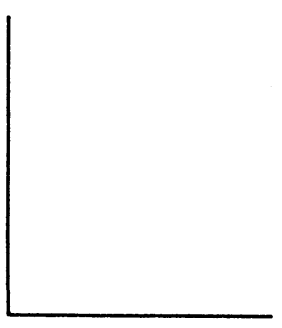

Figure 3

The difference between the two readings of the comparative conditional is schematized in Figure 2. Here the paired scales are seen as a twodimensional scalar model (Fillmore, Kay, and O'Connor 1988).

In Figure (2a), the graphed identity function represents the link between scalar variables: as there is an increase along one dimension of the model, there is an increase along another dimension. Figure (2b) represents the fixed-value reading; equivalent degrees of two scalar properties are represented by a single point equidistant from the origin along both dimensions. These readings are closely aligned; one might say that they differ only in the number of coordinates plotted within the scalar model. It therefore seems reasonable that the two meanings should find expression in the same syntactic template.

Diachronic evidence suggests that this template is ambiguous rather than vague with respect to these two readings in question. A search of comparative conditional examples within a computerized corpus 6 yields no clear instances of the constant reading in early Latin. Examples like those in (9) appear to be absent from the works of Plautus and Terence, for instance Granted, the supply of extant early Latin texts in not extraordinarily large. Nevertheless, this absence is suggestive. One might reasonably hypothesize that the constant reading represents a semantic reanalysis of the linked-scales reading - a meaning extension which preserves the comparative syntax better suited for expressing the original reading.

The ambiguity of a comparative conditional sentence is presumably resolvable via linguistic or extralinguistic context. Linguistic context includes verbal aspect. The instantiation of a range of scalar values prototypically involves the acquisition of those values over time. The requisite temporal extension is evoked by imperfective aspect, which, according to Comrie (1976: 24), makes "explicit reference to the internal temporal struc- 
ture of a situation". In Latin, the imperfective-perfective distinction is grammatically encoded in the past. In the present, the imperfective construal may be a direct function of Aktionsart, or it may emerge from the interaction of Aktionsart with tense. One variety of imperfectivity is habituality: a protracted, possibly iterated state of affairs. Sentence (1) contains the activity verb voluto ('I ponder'). Its present inflection is inconsistent with an episodic interpretation, the latter of which requires full instantiation at speech time. The verb thereby receives an iterative habitual interpretation: there are a number of instances in which the speaker mulls over the troublesome situation; each successive instance inspires greater grief. In sentence (6), both main- and subordinate-clause predicates, accedebat ('approachs') and fiebat ('becomes'), are grammatically imperfective. The imperfective construal associated with accedebat is nonhabitual or, in Comrie's terms, continuous. The approach is viewed in process, as the enemy reachs its destination. The imperfective fiebat evokes an iterative habitual scene: there are successive transitions to higher numerical values for fugitives slaughtered. The sentence as a whole charts a course of development over time: the enemy gradually comes closer to its goal and casualties gradually mount up. With respect to its aspectual properties, (6) is similar to sentence (13):

(13)

Quanto ille plura miscebat, how-much:ABL that:NOM more:ACC mixed:3SG:IMP:IND:ACT

tanto hic magis in dies

that-much:ABL this:NOM more in days:ACC

convalescebat.

grew-stronger:3SG:IMP:IND:ACT

'The more plots [Clodius] mixed up, the stronger [Milo] became day by day.'

Cicero, Pro Milone 25.8

In (13), the subordinate-clause imperfective evokes an iterative habitual intepretation: the total number of plots hatched grows on each occasion that Clodius executes a plan. The main-clause imperfective receives a continuous interpretation: Milo's strength improves each day during the period of Clodius' machinations. In (1), (6) and (13), adduction of a range of values for the paired variables arises from the view of a situation as unfolding over time. For each time within the interval for which the situation obtains, one pair of coordinates is plotted. This protracted situated may be "digitized" - divided into sub-episodes of pondering, etc. 
- or continuous. The variable reading does not, however, devolve upon the realization of a given imperfective situation at a reference time. As noted by Fillmore (1987), the comparative conditional can also express a generally valid correlation or a contingent prediction. Examples of these uses are given in (14a-b), respectively:
a. ...qui quidem quo severior who:NOM indeed which:ABL more-severe:NOM
'Indeed, the more severe and sad someone is, the more witty the remarks that person makes tend to appear.'
Cicero, De Oratore 2.61.289
b. Suos hortatur uti quanto
his:ACC urges:3SG:PRES:IND:PASS that how-much:ABL
sibi in proelio minus pepercissent,
selves:DAT in battle:ABL less spared:3PL:PAP:SUBJ:ACT
tanto tutiores fore.
that-much:ABL safer:NOM be:INF:FUT
'He urged his men that the less they had spared themselves in battle, the safer they would be.'
Sallust, De Bello Iugurthino 107.1

In interpreting these atemporal correlations, the speaker adduces a two-dimensional scalar model. In (14a), one dimension of this model ranks orators with respect to their dolorousness; the other dimension ranks witticisms with respect to their humorous effect. For each ranconteur - witticism pairing, values assigned to the arguments within the two dimensions are identical, and an identity function can be plotted over pairings, as in Figure 2a. The increase in value of the paired variables does not occur over time, as in (6), for example, but only as one "scans" the array of such pairings. For each pairing, a given degree of gloominess entails an equivalent degree of wit. Sentence (14b) has a similar atemporal construal. The increase along the dimensions of temerity and troop safety occurs as one considers the array of possible world-outcome pairings. These examples 
demonstrate that the variable reading is invoked whether values equated hold for phases within a time span (as in (6)) or individuals (situations or entities) within an ordered set (as in (14)).

While the variable interpretation does not entail imperfectivity, it is incompatible with perfective aspect. Perfectively described situations represent events. Such eventualities involve a set terminal point or inherent goal. As noted by Herweg (1991: 367), "[t] $]$ he feature of telicity gives events a definite temporal bound, which allows them to be temporally located within a time span". Because events are fully instantiated at speech time, they are reported in the past. An event is an individuated entity, associated with a unique point of culmination. Events involve one set of participants and a single time of occurrence. The event construal is then incompatible with a correlation over entities or over times. The presence of perfective aspect will thus unambiguously evoke the constant interpretation. In (2), for example, the perfective predicate conruit ('he fell') has an episodic construal; only one value for the seriousness of the downfall, rather than a range of such values, can be attached to that unique event.

While perfective aspect entails the constant interpretation, the reverse is not the case: the constant interpretation is available when a scene is construed imperfectively. In sentence (9b), for example, constants are equated, although each clause contains an imperfective predicate: erant ('were') and adferebat ('brought'). Because imperfective predicates are present, a variable interpretation is not precluded: 'the more charming the letter, the greater the sorrow that this misfortune brought'. This interpretation seems far fetched, however: it is unlikely that the letter in question (containing news of the death of Caesar's daughter, Julia) became more moving in the course of its reading, or that the reader became more sorrowful as he read. The imperfective predicates, unlike, e.g., accedebat in (6), do not appear to provide an internal perspective on an event during the course of its evolution over time. In (9b), aspectual choices seem to be dictated by considerations of the discourse organization. According to Hopper (1979), foregrounded events within a story line tend to be punctual, and hence are typically coded perfectively. By contrast, Hopper notes, "verbs of the durative/stative/iterative type" are used to provide background, "supportive material which does not itself narrate the main events" (p. 213). Within the framework of Discourse Representation Theory, these observations are reflected in the axiom that events advance the reference time of the narrative, whereas states do not (Herweg 1991). While the inherent lexical 
aspect (perfect or imperfect) will typically be manifested in the corresponding grammatical aspect, this need not be the case. Slobin and Bocaz (1989: 7) argue that "aspect can be flexibly used to indicate the way in which the narrator conceives of events, independent of the Aktionsart of the verb". A direct mapping of Aktionsart to grammatical aspect is found in the subordinate clause of the comparative conditional in (9b). The imperfective copula attributes to the letter in question a property (that of being touching) which provides narrative background - motivation for the event of grieving for Caesar's loss. This grieving event is reported in the perfective, dolui. In (9c), by contrast, one finds an "override" of inherent aspect: the copula is perfective. Here, the copula is used to refer to an episode which advances the narrative. First, the unarmed general returns to Italy; second, his return is gratifying to the people (i.e., inspires relief among them). In the main clause of $(9 \mathrm{~b})$, an inherently perfective event, that of "bringing something forward", is coded by an imperfective predicate, adferebat. Again, the imperfective provides motivation for the foregrounded event: the fact that the letter imparts sadness explains the narrator's reaction. The equivalence between degrees of charm and sadness inspired is then wholly backgrounded within the narrative. ${ }^{7}$ The equated values are both high values $v i s-\grave{a}$-vis their respective scales; the equation itself explains the author's acute grief, expressed in his intial exclamation. Hence, the equation of fixed values is consistent with imperfective aspect. Perfective aspect is not a reliable concomitant of the constant reading. When aspect cannot decide the case between the two readings, an appeal to extralinguistic context is often in order.

Extralinguistic context includes knowledge of what properties can be causally linked. Again, the aspectual features of (9a) do not disallow a variable interpretation: 'the safer the road, the longer it became'. This reading, however, requires an unusual background assumption: the safety of the road influences its length. The nonconditional interpretation is thereby preferred in this instance.

\section{Conclusion}

The comparative conditional in Latin, like its English analog, represents a formal idiom. While its syntactic properties are regular, its semantic properties are idiosyncratic. Among these idiosyncracies is its polysemous interpretation. Although the meaning alternation in question arises in large 
measure from alternate readings of the paired comparative phrases, it is not reducible to an ambiguity of the comparative form per se. The "fixed value" interpretation of the comparative is constructionally linked; it is present only within the comparative conditional (and perhaps also the double-comparative construction of (10)). The existence of polysemous syntactic templates is problematic for those syntactic theories in which constructional meanings arise solely through semantic composition: if the meaning of a grammatical construct is solely a function of the meaning of constructional subparts, no more than one meaning should be calculable for any complex expression. Constructional polysemy is not so troubling for those grammatical theories which license departures from strict semantic composition. Among these theories are Construction Grammar (Fillmore, Kay, and O'Connor 1988; Fillmore and Kay 1991) and Cognitive Grammar (Langacker 1987, 1988, 1991). Within such theories, constructional polysemy is increasingly recognized as an appropriate object of theoretical inquiry. Indeed, Langacker argues (1988: 3), "phenomena like [...] semantic extension are central to the proper analysis of [both] lexicon and grammar". Goldberg (1992) applies the CG framework in examining the network of senses associated with the English ditransitive valence. These frameworks represent the grammar as a repertoire of form-meaning pairings, lexical, phrasal and clausal. This repository contains formal idioms - syntactically complex constructs with which meanings must be associated holistically. These represent instances in which the meaning of the syntactic construct is not calculable, but is instead conventional. Such constructions then express meanings in much the same way that words express meanings. Like words, they are "learned separately as individual whole facts about pieces of language" (Fillmore, Kay and O'Connor 1988: 504). Just as speakers may recognize more or less tenuous derivational relationships among words, they may identify semantic and syntactic commonalities which link a given formal idiom to the grammar at large. The pervasive nature of lexical polysemy is commonly noted (cf. Lakoff 1987). The recognition of a semantic kinship between words and formal idioms makes possible a principled account of constructional polysemy. 
Author's address:

(Received March 11th, 1992)

Laura A. Michaelis

Dept. of Linguistics, CB 295

University of Colorado

Boulder, CO 80309

USA

\section{NOTES}

1. An earlier version of this paper was presented at the eighteenth annual meeting of the Berkeley Linguistics Society. For valuable suggestions and criticisms, I would like to thank Charles Fillmore, Paul Kay, Jean-Pierre Koenig, Knud Lambrecht, Eve Sweetser and an anonymous reviewer. Errores praestare nemo illorum potest.

Abbreviations used in the interlinear glosses ,apart from the "normal" ones are as follows: PAP: past perfect, and SUBJ: UNC subjunctive.

2. In the version of scalar semantics assumed by Fillmore, Kay and O'Connor, scales do not exist independently of the elements ordered within them. That is, any given scale simply consists of entities ranked with respect to the degree to which they manifest a given property. I will assume here a slightly modified version of this view, in which scales consist of degrees to which numerical values may be assigned, and that such such degrees are "loci" at which the ranked entities are placed. The revised view is reflected in one description of correlative semantics employed here: values assigned to the scalar loci occupied by two entities on one or two scales (or by one entity on two scales) are equal. An abbreviated form of this description is the following: scalar values assigned to one or two entities are equal. Alternatively, we can refer to the placement of two entities at the same position on two property scales, etc. Both modes of description are employed here.

3. There are instances of the fixed-value reading of the comparative conditional that do not involve this semantically unmotivated use of the comparative. These are cases in which two fixed-standard comparatives are equated:

(i) Quo pluris est res publica

how-much:ABL more:GEN is:3SG:PRES:IND matter:NOM public:NOM

quam consulatus aut praetura, eo

than consulship:NOM or praetorship:NOM that-much:ABL

maiore cura illam administrari quam haec

greater:ABL care:ABL that:ACC administer:INF:PRES:PASS than these:ACC

peti debere

seek:INF:PRES:PASS must:INF:PRES

'By as much as the whole republic is greater than the consulship or the praetorship, with that much greater care must it be administered than these offices be sought.'

Sallust, De Bello Iugurthino 85.2 
Here the CompPhrases quo pluris ('by how much more') and eo maiore ('by that much greater') are fixed-standard comparatives, as indicated by the presence of quam-clauses coding the standards of comparison. In this sentence, the degree of importance of the republic and the extent of administrative care thereby required are asserted to be equal. Each of these degrees is also asserted to be greater than that associated with a comparative standard. Thus, the degree of importance attached to the republic is greater than that attributable to political offices. Similarly, the equivalent degree of administrative care that must be exercised is greater (or ought to be greater) than the care with which political offices are sought. Sentences like (i) thus equate two compared values; they are four-part proportional analogies. The interpretation of (i) appears derivable from an integration of correlative and comparative semantics alone. By contrast, as argued, the two readings of the comparative conditional discussed are not so derivable. In the case of the linked-scales reading, a specialized form of comparison is invoked. In the case of the fixed-value reading, the semantic contribution of the comparative is "factored out".

It has been suggested that the comparatives in (9a) might be regarded as fixed-standard comparatives akin to those in (i). That is, the appropriate translation of (9a) might be: 'By how much safer one road was than the other, by that much longer that road was than the other'. Under this reading, the sentence presupposes that the road at issue is safer than the Caudine road; this information is expressed by the subordinate clause. That is, the first road is the target of a safety comparison in which the Caudine road is the standard. The target of this background comparison is itself the standard against which a second comparison is asserted. The presupposed material representing the first half of the proportion can be accommodated insofar as the exceptionally safe nature of this broad road has been under discussion. A problem for this analysis of (9a) arises when one considers the assertive component of the sentence under the interpretation suggested. Under the fixed-standard reading, the sentence asserts that the first road is longer than the Caudine road (the second half of the proportion). That the assertion vis$\grave{a}$-vis length has not in fact been made is evidenced by the context immediately following the correlative sentence: the author asserts that the Caudine road is shorter (Altera...brevior). This assertion would be oddly uninformative if the preceding correlative were interpreted as a fixedstandard comparative akin to (i). For this reason, it seems reasonable to regard (9a) as an instance of the constant reading: the authors equates safety and length values for one road, without reference to comparable values for the second road.

Some comparative conditional sentences may then be three-ways ambiguous. Without context, the CompPhrases of (ii) may be interpreted as moving-standard comparatives, fixed-standard comparatives, or "pro-forma comparatives" (i.e., those with no clear comparative target). Three translations of (ii) are given, the first involving correlated scales, the second equation of comparatives (cf. (i)) and the third equation of 'noncompared' fixed values:

(b)

Quo plures erant, eo maior
how-much:ABL more:NOM were:3PL:IMPERF:IND that much:ABL greater:NOM
caedes fuit
slaughter:NOM was:3SG:PERF:IND
1. 'The more there were, the greater the slaughter became.'
2. 'By how much more numerous they were than some other group, by that much
greater their slaughter was than that of the other group.'
3. 'The slaughter was as great as they were numerous.'
Livy 2.51

The first reading can be discarded a priori, given the perfective verb fuit of the main clause. This verb form supplies an episodic construal of the massacre, rather than a view of its development over time. (The imperfective predicate fiebat, 'was becoming', welcomes the linked-scales 
reading, as shown in (6).). Context must decide between the latter readings. In fact, context points to the second reading given. The context immediately preceding (ii) is given in (ii):

(iii)Capiti deinde eadem arte sunt qua

Captured:NOM finally same:ABL art:AB are:3PL:PRES:IND which:ABL

Fabios [...] praecipitaverunt in insidias.

Fabii:ACC fell-headlong:3PL:PERF:IND in ambush:ACC

'Finally they were captured by that same art by which they had captured the Fabii

$[\ldots]$ They fell headlong into the ambush.'

Hence, the comparatives of (ii), plures and maior, have as comparative standards the number of the Fabii and magnitude of their slaughter. Sentence (ii) may accordingly be translated: "by how much more numerous they were than the Fabii had been, by that much greater was their slaughter'. Thus, (ii) has an interpretation analogous to that of (i) - the only difference being that in (ii) the comparative standards are contextually supplied rather than expressed via quam-clauses.

4. It has been suggested that the comparative seen in sentences like (9) is that comparative which elsewhere codes a somewhat pronounced degree of a given property. Hence, the comparative fortior ('stronger') can be sometimes be translated as 'rather strong'. The standard of comparison in such instances is a norm for the scalar property in question. This reading of the comparative is also seen in English, in expressions like the finer things and $a$ better class of people. It seems unlikely that this is the reading of the comparative evoked in (9). In (9b), for example, the comparative suaviores (lit. 'sweeter') cannot reasonably be interpreted as 'rather charming'; the author has previously noted that the letter in question is charming to a very high degree. It might then be argued that the comparative under this reading is compatible with a high degree of the property as issue. The validity of this analysis is impugned by examples in which the constant reading is used in a limiting sense. In (12), for example, acceptius (lit. 'more acceptable') does not mean either 'rather acceptable' or 'extremely acceptable'. The emperor's investment was only marginally acceptable to the people, i.e., tolerable only in view of certain mitigating circumstances. A final counterargument is the following: the 'rather' comparative does not apparently welcome an ablative of measure. The comparative conditional comparatives of (9) are, of course, accompanied by such degree-markers.

5. Evidence of this sort is a little suspect: the replacement discussed is sporadic even within the works of a given author, and typically only one clause is affected (main or subordinate). Nonetheless, the replacement does not seem to apply to comparative conditional instances having the correlated-scales reading (at least not in Classical Latin).

6. The Packard Humanities Institute corpus is a computerized data base containing all extant Latin texts.

7. Background as used by Hopper is distinct from pragmatic presupposition (Lambrecht, forthcoming). While the entire comparative condition is narrative background in (9b), only the subordinate clause expresses pragmatically presupposed material (that the letter was touching). 


\section{REFERENCES}

Comrie, Bernard. 1976. Aspect. Cambridge: Cambridge University Press.

Fillmore, Charles J. 1987. "Varieties of conditional sentences". Proceedings of the Eastern States Conference on Linguistics 3: 163-182.

Fillmore, Charles J.; Kay, Paul; and O'Connor, Mary Catherine. 1988. "Regularity and idiomaticity in grammatical constructions: The case of let alone". Language 64: 501-538.

Fillmore, Charles J., and Kay, Paul. 1991. Construction grammar. Unpublished ms, University of California, Berkeley.

Goldberg, Adele. 1992. "On the inherent semantics of argument structure: The case of the English ditransitive". Cognitive Linguistics. 3: 37-74.

Herweg, Michael. 1991. "A critical examination of two classical approachs to aspect". Journal of Semantics 8: 363-402.

Hopper, Paul. 1979. "Aspect and foregrounding in discourse". In: Givón, T. (ed.), Syntax and semantics, vol. 12: Discourse and syntax, 213-241. New York: Academic Press, Inc.

Lakoff, George. 1987. Women, fire and dangerous things: What categories reveal about the nature of the mind. Chicago: University of Chicago Press.

Lambrecht, Knud. Forthcoming. Information structure and sentence form. Cambridge: Cambridge University Press.

Langacker, Ronald W. 1987. Foundations of cognitive grammar, volume 1. Stanford: Stanford University Press.

Langacker, Ronald W. 1988. "An overview of cognitive grammar". In: Rudzka-Ostyn, Brygida (ed.), Topics in cognitive linguistics, 3-48. Amsterdam:Benjamins.

Langacker, Ronald W. 1991. Foundations of cognitive grammar, volume 2. Stanford: Stanford University Press.

McCawley, James D. 1988. "The comparative conditional construction in English, German and Chinese". In: Hall, Kira et al. (eds), The Proceedings of the Fourteenth Annual Meeting of the Berkeley Linguistics Society, 176-187. Berkeley: Berkeley Linguistics Society, Inc.

Slobin, Dan; and Bocaz, Aura. 1989. Learning to talk about movement through time and space: The development of narrative abilities in Spanish and English. [Berkeley Cognitive Science Report, 55.] Berkeley: Institute of Cognitive Studies. 


\section{LATIN AUTHORS CITED}

Early Latin

Plautus (d. 184 BCE) Cicero (d. 43 BCE)

Terence (d. 159 BCE) Sallust (d. 35 BCE)
Ciceronian Latin
Later Latin

Nepos (d. 24 BCE)

Livy (d. $17 \mathrm{CE}$ )

Ovid (d. 18? CE)

Velleius (fl. $30 \mathrm{CE}$ )

Tacitus (d. 120? CE)

Apuleius (d. $160 \mathrm{CE}$ ) 